\title{
Prevalence and outcomes of olfactory and gustatory dysfunctions in hospitalized SARS-CoV-2-infected patients
}

\author{
Mohammad Salah Mahmoud*i(, Mohamed Shehata Taha, Ossama Ibrahim Mansour, Mohamed Amir, \\ Tarek A. Hamdy, W. F. Ezzat, A. H. Mohamed, Michael Rezk, Mina Fayez Saleeb and Mena Maher Nassif
}

\begin{abstract}
Background: The prevalence of olfactory/gustatory dysfunctions among hospitalized SARS-CoV-2-infected patients is highly variable between different studies, ranging from $5.6 \%$ in the Asian population to $86 \%$ in the European population. The study aimed to detect the prevalence and the recovery of olfactory/gustatory dysfunctions in hospitalized SARS-CoV-2-infected patients in an Egyptian tertiary care center. A total of 579 hospitalized patients were enrolled. Demographic data as well as upper respiratory tract symptoms including olfactory/gustatory dysfunctions and other risk factors were documented. Then the recovery of olfactory/gustatory dysfunctions after 6 months was followed up.

Results: $50.6 \%$ had olfactory/gustatory dysfunctions ( $24.2 \%$ had a total smell and taste loss). A logistic regression analysis revealed a statistical significance between olfactory/gustatory dysfunctions and female gender and presence. Most patients (88.4\%) reported partial or complete recovery during the 6 months ( $28.0 \%$ and $60.4 \%$, respectively), while $11.6 \%$ of patients did not recover. The median time to start recovery was 3 days, and the median time to the best recovery was 22 days.

Conclusions: Olfactory/gustatory dysfunctions should be recognized for early detection of COVID-19 infection. Most recovery of olfactory/gustatory dysfunction in COVID-19 infection starts within 3 days and reaches the best recovery within 19 to 24 days. Female gender and the presence of general symptoms are associated with olfactory/gustatory dysfunctions in the hospitalized COVID-19 patients.
\end{abstract}

Keywords: Olfactory dysfunctions, Gustatory dysfunctions, SARS-CoV-2, Hospitalized, Prevalence, Recovery, Outcome

\section{Background}

In December 2019, coronavirus disease 2019 (COVID19) outbroke in China and then rapidly spread worldwide [1]. In COVID-19 patients, the main symptoms were fever and cough [2]. Moreover, some patients report upper respiratory symptoms especially olfactory OD and gustatory dysfunctions GD [3].

The prevalence of OD and GD among hospitalized patients is highly variable between different studies,

*Correspondence: drsalahmady@gmail.com

Otorhinolaryngology Department, Faculty of Medicine, Ain Shams University, Cairo, Egypt ranging from $5.1 \%$ and $5.6 \%$ in a Chinese study [4] to $86 \%$ and $88 \%$ in a European study [5], for OD and GD, respectively.

The duration of recovery is not clear. Various studies stated a rapid recovery in most of the patients, while some patients had later recovery or persistent OD and GD [6, 7]. It has also been noticed abnormal recovery of taste and smell in the form of parosmia and parageusia [8].

Our study aim was to determine the prevalence of olfactory and gustatory dysfunction in hospitalized COVID-19 patients and to evaluate the timing and pattern of recovery in a tertiary care center. 


\section{Methods}

\section{Subjects and setting}

This is a prospective study to evaluate the prevalence and recovery of olfactory and gustatory disorders among hospitalized SARS-CoV-2-infected patients in a tertiary care center from July 2020 to January 2021.

A total of 579 hospitalized patients (18 to 70 years old) with confirmed SARS-CoV-2 infection by RT-PCR, with mild to moderate SARS-CoV-2 infection [9], were enrolled in the study, while patients with missing data, no olfactory or gustatory impairments, negative RTPCR for SARS-CoV-2 infection, previous olfactory or gustatory impairment, previous sinonasal disease or surgery, and neuropsychiatric disorders; patients with SARS-CoV-2 infection severe symptoms; and patients who lost follow-up were excluded from the study.

Patients were interviewed by a physician to document a detailed history of olfactory and gustatory impairments together with any related symptoms. Six months later, a follow-up interview was conducted to document recovery. Other data included age, sex, smoking, chronic medical disorders, risk factors for contracting SARS-CoV-2 infection, and associated COVID-19 symptoms.

The analysis of olfactory dysfunction was done to characterize variation, timing, course, duration, associated symptoms, and recovery. All patients signed informed written consent. All patients' data were dealt with complete confidentiality.

\section{Statistical methods}

Data were analyzed using IBM॰ SPSS $\odot$ Statistics version 26 (IBM@ Corp., Armonk, NY). Categorical variables are presented as numbers and percentages, and inter-group differences are compared using the Pearson chi-squared test or Fisher's exact test. Time to event analysis is done using the Kaplan-Meier method.

Multivariable binary logistic regression analysis was used to identify predictors of occurrence or recovery of smell/taste loss in COVID-19 patients. Factors associated with the outcome of interest at the $P<0.2$ level by bivariate analysis are selected for entry in multivariable logistic regression to identify independent predictors. $P$-values $<0.05$ are considered statistically significant.

\section{Results}

The study enrolled 579 participants (275 males and 304 females). For past medical history, 1.9\% had DM, $25 \%$ had recent URTI, $17.4 \%$ were smokers, $13.8 \%$ had recent head trauma, $35.2 \%$ of patients were healthcare workers, and $15.5 \%$ were in close contact with confirmed cases (Table 1).
Table 1 Epidemiological characteristics of the study population

\begin{tabular}{lll}
\hline Variable & Count & Valid \% \\
\hline Sex & & \\
M & 275 & $47.5 \%$ \\
F & 304 & $52.5 \%$ \\
Medical history & & \\
Smoking & 101 & $17.4 \%$ \\
Heart disease & 130 & $22.5 \%$ \\
DM & 11 & $1.9 \%$ \\
Other comorbidities & 30 & $5.2 \%$ \\
Recent URTI & 147 & $25.4 \%$ \\
Recent head trauma & 80 & $13.8 \%$ \\
Exposure to an identified source of COVID-19 & 187 & $32.3 \%$ \\
Risk factors for CovID-19 & & \\
Nil & 245 & $42.3 \%$ \\
Healthcare worker & 204 & $35.2 \%$ \\
First responder & 7 & $1.2 \%$ \\
Close contact with confirmed case & 90 & $15.5 \%$ \\
Homeless & 16 & $2.8 \%$ \\
Travel to high-prevalence areas & 14 & $2.4 \%$ \\
Others & 3 & $0.5 \%$ \\
\hline
\end{tabular}

Table 2 Prevalence of general symptoms of COVID-19

\begin{tabular}{lll}
\hline Variable & Count & Valid \% \\
\hline General symptoms of COVID-19 & & \\
Fever & 324 & $56.0 \%$ \\
Chills & 84 & $14.5 \%$ \\
Fatigue & 219 & $37.8 \%$ \\
Cough & 263 & $45.4 \%$ \\
Headache & 227 & $39.2 \%$ \\
Nasal congestion & 109 & $18.8 \%$ \\
Runny nose & 65 & $11.2 \%$ \\
GIT symptoms & 73 & $12.6 \%$ \\
Other symptoms & 19 & $3.3 \%$ \\
\hline
\end{tabular}

COVID-19-related symptoms varied from cough (45.4\%), fatigue (37.8\%), headache $(39.2 \%)$, nasal congestion, and runny nose, with the most common symptom being fever (56.0\%) (Table 2).

\section{The pattern of smell/taste loss}

$50.6 \%$ of hospitalized SARS-CoV-2-infected patients suffered from altered smell/taste. Half of them $(24.2 \%$ of all participants) had a total smell and taste loss. Most of the patients had sudden onset of anosmia (64.8\%). 76.5\% had other upper respiratory symptoms before the start of smell/taste symptoms (Table 3). 
Table 3 Prevalence and pattern of abnormalities of smell/taste

\begin{tabular}{|c|c|c|}
\hline Variable & Count & Valid \% \\
\hline \multicolumn{3}{|l|}{ Prevalence of specific forms of smell/taste abnormality } \\
\hline Nil & 286 & $49.4 \%$ \\
\hline Total smell loss & 9 & $1.6 \%$ \\
\hline Total taste loss & 60 & $10.4 \%$ \\
\hline Total smell and taste loss & 140 & $24.2 \%$ \\
\hline Partial smell loss & 16 & $2.8 \%$ \\
\hline Partial taste loss & 18 & $3.1 \%$ \\
\hline Partial smell and taste loss & 50 & $8.6 \%$ \\
\hline \multicolumn{3}{|l|}{ The overall prevalence of smell/taste abnormality } \\
\hline No smell/taste abnormality & 286 & $49.4 \%$ \\
\hline Smell/taste abnormality of any form & 293 & $50.6 \%$ \\
\hline \multicolumn{3}{|l|}{ The onset of anosmia/dysgeusia to the diagnosis of COVID-19 } \\
\hline Before diagnosis of COVID-19 & 164 & $56.0 \%$ \\
\hline After diagnosis of COVID-19 & 129 & $44.0 \%$ \\
\hline \multicolumn{3}{|l|}{ Other symptoms before the development of anosmia/dysgeusia } \\
\hline No other symptoms before the development of anosmia/dysgeusia & 69 & $23.5 \%$ \\
\hline Other symptoms present before the development of anosmia/dysgeusia & 224 & $76.5 \%$ \\
\hline \multicolumn{3}{|l|}{ The onset of anosmia/dysgeusia } \\
\hline Gradual & 103 & $35.2 \%$ \\
\hline Sudden & 190 & $64.8 \%$ \\
\hline
\end{tabular}

Table 4 Course and prognosis

\begin{tabular}{lll}
\hline Variable & Count & Valid \% \\
\hline $\begin{array}{lll}\text { Recovery of smell/taste loss } \\
\text { Smell/taste loss did not improve }\end{array}$ & 34 & \\
$\begin{array}{l}\text { Smell/taste loss improved } \\
\text { Ultimate outcome }\end{array}$ & 259 & $88.4 \%$ \\
No improvement & & \\
Partial recovery & 34 & $11.6 \%$ \\
Complete recovery & 82 & $28.0 \%$ \\
\hline
\end{tabular}

Most of the patients improved $88 \%$ either completely $60 \%$ or partially $28 \%$ and only $11.6 \%$ did not recover from anosmia/parosmia (Table 4; Fig. 1). The median time to start recovery was 3 days, while the median time to best recovery was 22 days, and the median time to complete cure was 75 days (Figs. 2, 3, and 4).

\section{Relation between smell/taste loss and risk factors}

The results revealed a statistically significant relation between olfactory and gustatory dysfunctions and female gender $(P$-value $<0.001)$, also smoking $(P$-value $0.008)$, heart diseases ( $P$-value 0.019$)$, and presence of nasal symptoms $(P$-value 0.015$)$, while there was no relation between incidence and chronic pulmonary disease or DM (Table 5). By applying the multivariable binary logistic regression analysis, only female gender $(P$-value $<0.001)$ and presence of general symptoms ( $P$-value $<0.029)$ had a statistical significance, with 95\% confidence interval 1.285-2.782 and 1.066-3.292, respectively (Table 6).

By comparing no improvement versus partial/complete recovery, none of these risk factors was associated with partial or complete recovery (Tables 7 and 8). On the contrary, by comparing no/partial recovery versus complete recovery on the same risk factors, age $>50$, smoking, and heart diseases had a statistical significance $P$-value $0.014,0.009$, and 0.019 , respectively, while by applying the multivariable binary logistic regression analysis, only smoking has a statistical significance $P$-value of 0.003 (Tables 9 and 10).

\section{Discussion}

Starting in December 2019 in Wuhan (Hubei province, China), a novel coronavirus, designated SARS-CoV-2, has caused an international outbreak of a respiratory illness (COVID-19), rapidly evolving into a pandemic. Most cases are asymptomatic or self-limiting, but the clinical spectrum extends to severe progressive pneumonia with acute respiratory distress syndrome. Olfactory and gustatory dysfunctions are very characteristic symptoms of the disease. So, this study is primarily concerned with olfactory and gustatory dysfunctions during the pandemic, 


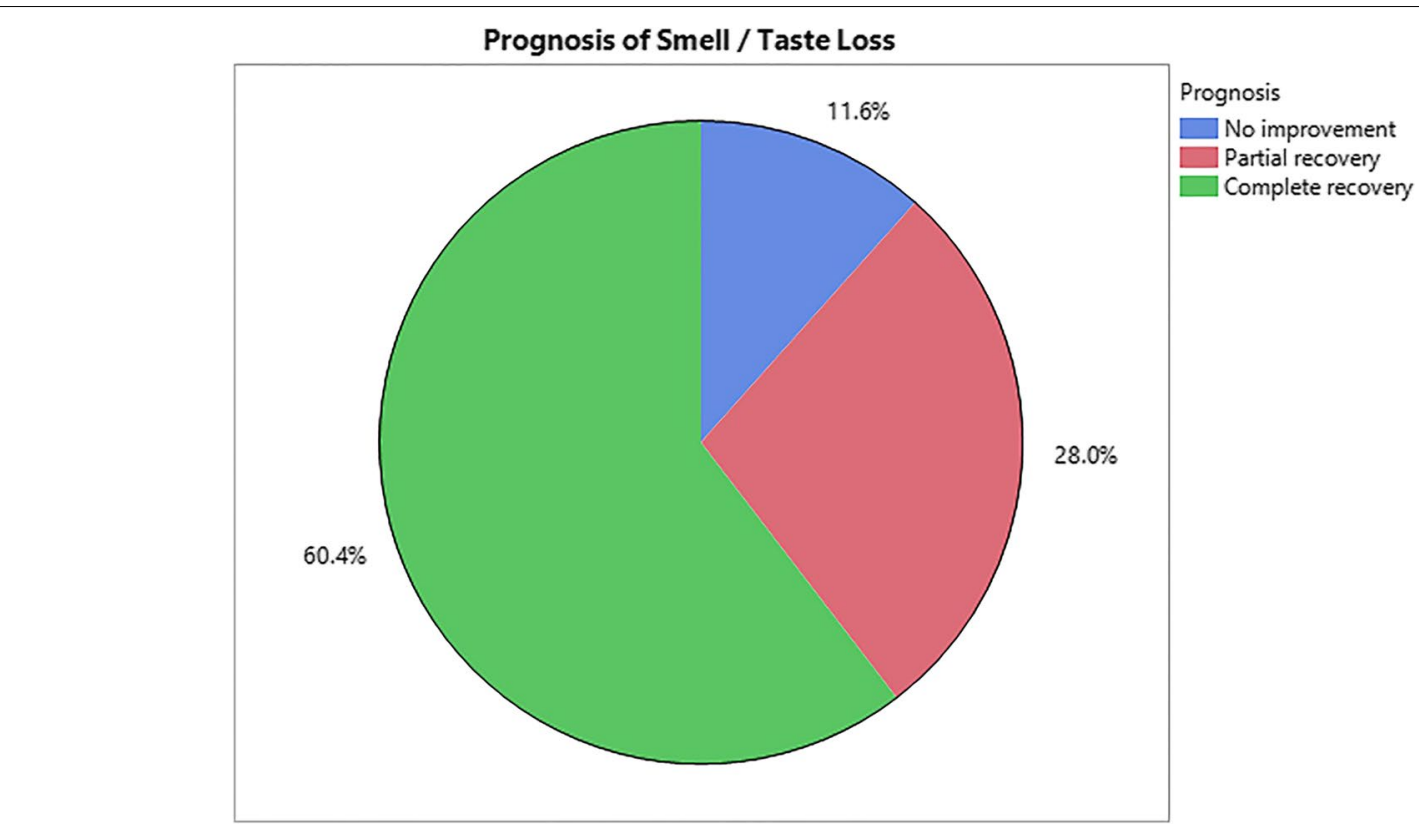

Fig. 1 Prognosis of smell/taste loss

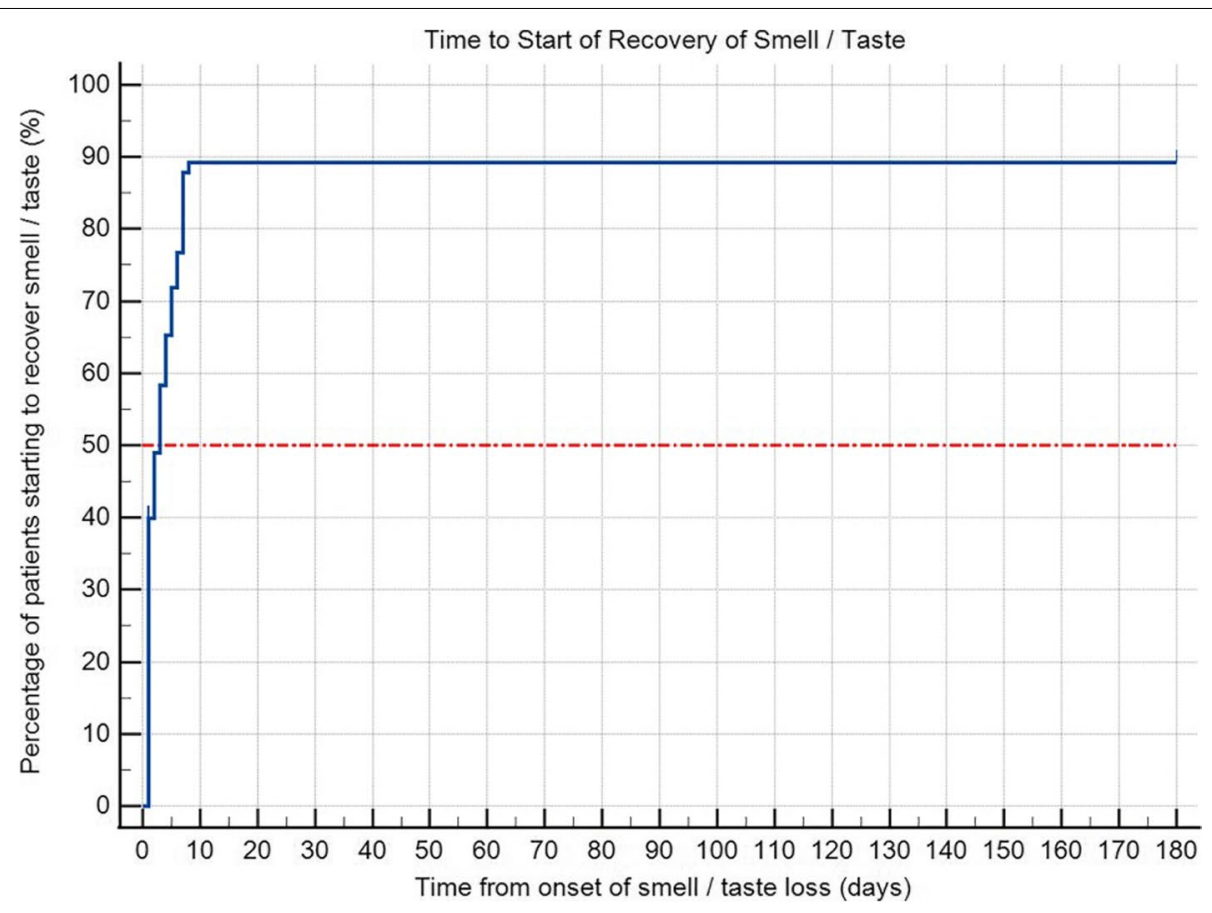

Fig. 2 Kaplan-Meier curve for the time to start of recovery. Median time to start of recovery $=3$ days. 95\% Cl could not be estimated

comprehensively evaluating the onset, course, and relation to the COVID-19 course and its symptoms.

We found that more than $50 \%$ of hospitalized SARS$\mathrm{CoV}$-2-infected patients suffered from olfactory and gustatory dysfunctions. Half of them $(24.2 \%$ of all participants) had a total smell and taste loss. Most of the patients had sudden onset of anosmia (64.8\%). $76.5 \%$ had other symptoms before the olfactory and gustatory dysfunctions. This result is close to what Meini et al. [10] has found that $42 \%$ of hospitalized 


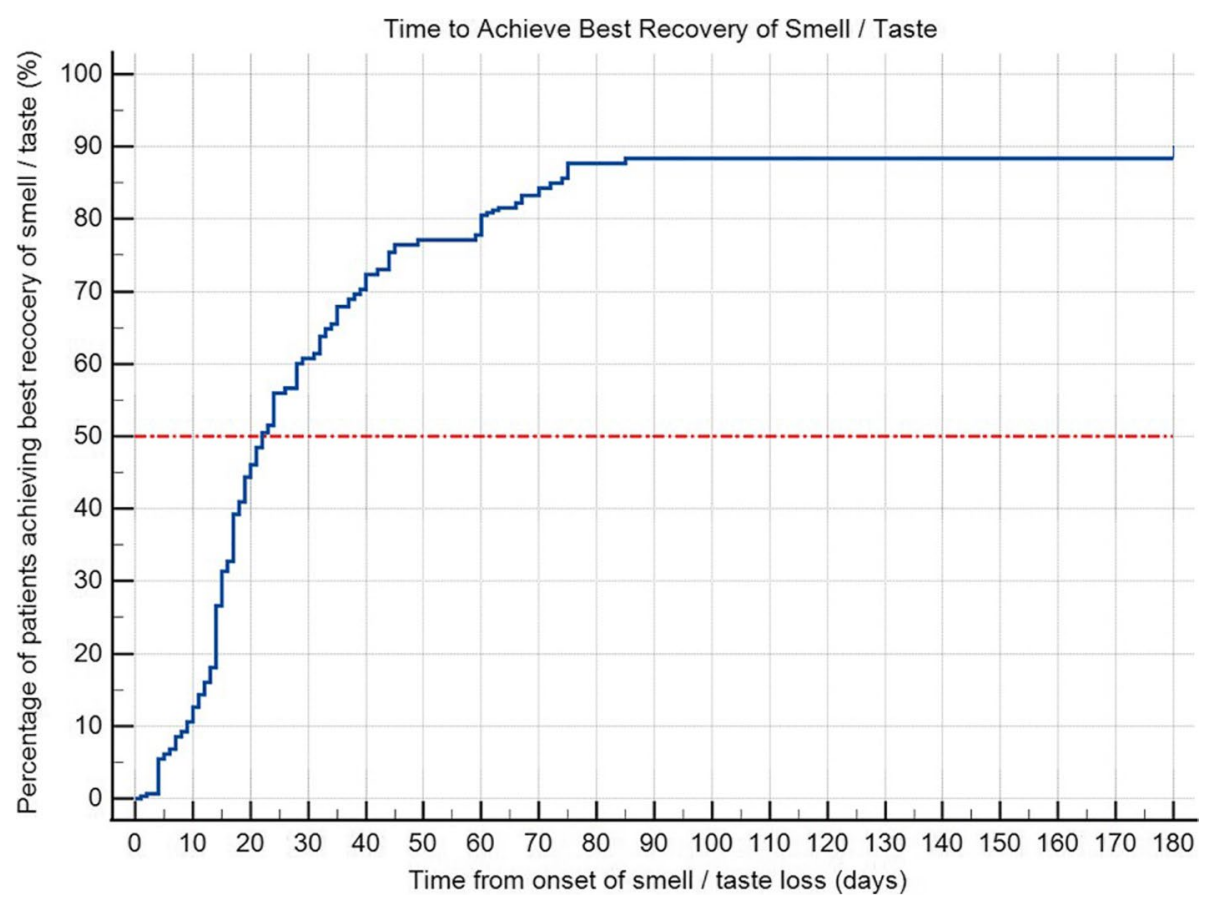

Fig. 3 Kaplan-Meier curve for the time to best recovery. Median time to best recovery $=22$ ( $95 \% \mathrm{Cl}=19$ to 24 ) days

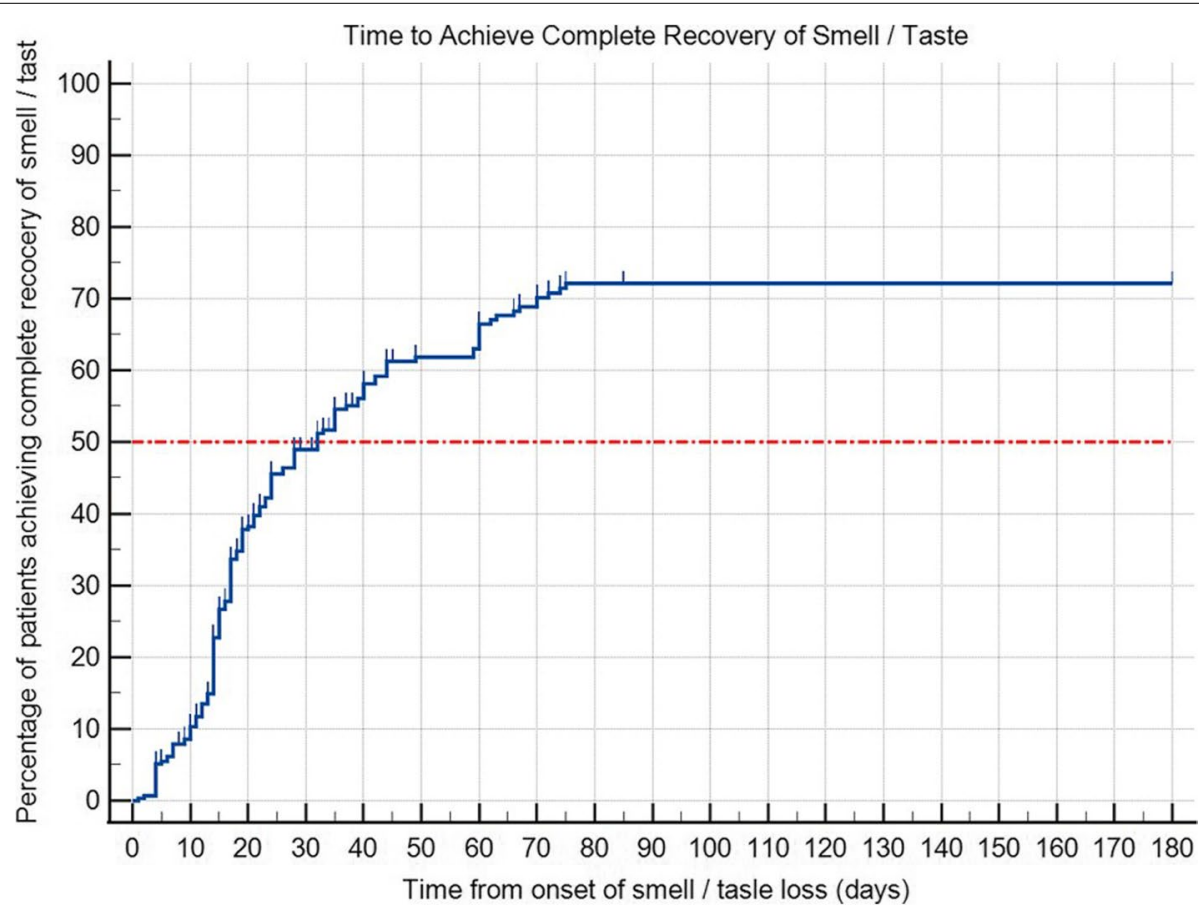

Fig. 4 Kaplan-Meier curve for the time to complete recovery. Median time to complete recovery $=75(95 \% \mathrm{Cl}=66$ to 85 ) days 
Table 5 Factors associated with smell/taste loss in COVID-19 patients

\begin{tabular}{|c|c|c|c|c|c|}
\hline \multirow[t]{2}{*}{ Variable } & \multicolumn{2}{|c|}{$\begin{array}{l}\text { No smell/ } \\
\text { taste loss ( } \mathrm{n} \\
=286 \text { ) } \\
\end{array}$} & \multicolumn{2}{|c|}{$\begin{array}{l}\text { Smell/taste } \\
\text { loss }(n=293)\end{array}$} & \multirow[t]{2}{*}{$p$-value ${ }^{\dagger}$} \\
\hline & $N$ & $\%$ & $n$ & $\%$ & \\
\hline Female sex & 121 & $42.3 \%$ & 183 & $62.5 \%$ & $<0.001$ \\
\hline Age $>50$ years & 121 & $42.3 \%$ & 104 & $35.5 \%$ & 0.093 \\
\hline Smoking & 62 & $21.7 \%$ & 39 & $13.3 \%$ & 0.008 \\
\hline Chronic pulmonary disease & 43 & $15.0 \%$ & 40 & $13.7 \%$ & 0.635 \\
\hline Heart disease & 76 & $26.6 \%$ & 54 & $18.4 \%$ & 0.019 \\
\hline $\mathrm{DM}$ & 5 & $1.7 \%$ & 6 & $2.0 \%$ & 0.792 \\
\hline General symptoms & 241 & $84.3 \%$ & 269 & $91.8 \%$ & 0.005 \\
\hline Nasal symptoms & 58 & $20.3 \%$ & 85 & $29.0 \%$ & 0.015 \\
\hline
\end{tabular}

Data are numbers ( $n$ ) and percentage (\%)

${ }^{\dagger}$ Pearson chi-squared test. Bold font means a statistical significance

COVID-19 patients had olfactory and gustatory dysfunctions

Also, this nearly matches what Saniasiaya et al. [11] found in their meta-analysis done on 83 studies and revealed that the prevalence of olfactory dysfunction in SARS-CoV-2-infected patients was $47.85 \%$. Olfactory dysfunction was observed in 54.40\% European, 51.11\% North American, 31.39\% Asian, and 10.71\% Australian SARS-CoV-2-infected patients. And these data match what we found among Egyptians 50.6\%, and this may highlight a higher incidence of olfactory dysfunction among Caucasians compared to Asians.

This study enrolled 579 participants, 275 (47.5\%) males and 304 (52.5\%) females; olfactory/gustatory dysfunctions were more dominant in females than in males (62.5\% of females had olfactory/gustatory dysfunctions). The higher susceptibility of females to olfactory and gustatory dysfunctions may be related to gender-related differences in the inflammatory process [12]. The female predominance in olfactory and gustatory dysfunctions was reported in several studies ranging from 61.9 to $74.6 \%$ [13-17]. On the contrary, other studies reported that males are more prone to these changes $[18,19]$. Also, in the current study, $35.2 \%$ of the hospitalized SARS$\mathrm{CoV}$-2-infected patients were healthcare workers. This could be due to more exposure to the virus [20] and most of the nursing staff are females.

Olfactory/gustatory dysfunctions have been reported as being significantly higher in SARS-CoV-2-infected patients versus patients with no SARS-CoV-2 infection with influenza-like symptoms $(68 \%$ and $71 \%$ vs 16 and $17 \%$, respectively) [21]. Some authors suggest that the pathophysiology of injury in SARS-CoV-2 infection is similar to that of other infections that cause central and peripheral neurologic deficits, while others hypothesize that the OD is not directly a result of neuronal cell injury and other supporting cells' damage appears more likely.

Table 7 Factors associated with partial/complete recovery of smell/taste in COVID-19 patients

\begin{tabular}{|c|c|c|c|c|c|}
\hline \multirow[t]{2}{*}{ Variable } & \multicolumn{2}{|c|}{$\begin{array}{l}\text { No } \\
\text { improvement } \\
(n=34)\end{array}$} & \multicolumn{2}{|c|}{$\begin{array}{l}\text { Partial/ } \\
\text { complete } \\
\text { recovery ( } \\
=259 \text { ) } \\
\end{array}$} & \multirow[t]{2}{*}{$p$-value ${ }^{\dagger}$} \\
\hline & $n$ & $\%$ & $n$ & $\%$ & \\
\hline Female sex & 20 & $58.8 \%$ & 163 & $62.9 \%$ & 0.642 \\
\hline Age $>50$ years & 17 & $50.0 \%$ & 87 & $33.6 \%$ & 0.060 \\
\hline Smoking & 4 & $11.8 \%$ & 35 & $13.5 \%$ & $1.000^{\ddagger}$ \\
\hline Chronic pulmonary disease & 8 & $23.5 \%$ & 32 & $12.4 \%$ & $0.106^{\ddagger}$ \\
\hline Heart disease & 6 & $17.6 \%$ & 48 & $18.5 \%$ & 0.900 \\
\hline DM & 0 & $0.0 \%$ & 6 & $2.3 \%$ & $1.000^{\ddagger}$ \\
\hline Chronic comorbidity & 16 & $47.1 \%$ & 105 & $40.5 \%$ & 0.468 \\
\hline General symptoms & 32 & $94.1 \%$ & 237 & $91.5 \%$ & $1.000^{\ddagger}$ \\
\hline Nasal symptoms & 11 & $32.4 \%$ & 74 & $28.6 \%$ & 0.648 \\
\hline
\end{tabular}

Data are numbers $(n)$ and percentage (\%)

† Pearson chi-squared test unless otherwise specified

${ }^{\ddagger}$ Fisher's exact test

Table 6 Multivariable binary logistic regression analysis for predictors of smell/taste loss in COVID-19 patients

\begin{tabular}{|c|c|c|c|c|c|c|c|c|}
\hline \multirow[t]{2}{*}{ Variable } & \multirow[t]{2}{*}{ B } & \multirow[t]{2}{*}{ SE } & \multirow[t]{2}{*}{ Wald } & \multirow[t]{2}{*}{ df } & \multirow[t]{2}{*}{$p$-value } & \multirow[t]{2}{*}{$\operatorname{Exp}(B)$} & \multicolumn{2}{|c|}{$95 \% \mathrm{Cl}$ for $\operatorname{Exp}(\mathrm{B})$} \\
\hline & & & & & & & Lower & Upper \\
\hline Female gender $(=1)$ & 0.637 & 0.197 & 10.461 & 1 & 0.001 & 1.891 & 1.285 & 2.782 \\
\hline Age $>50$ years $(=1)$ & -0.206 & 0.197 & 1.098 & 1 & 0.295 & 0.814 & 0.554 & 1.196 \\
\hline Smoking $(=1)$ & -0.325 & 0.264 & 1.514 & 1 & 0.219 & 0.723 & 0.431 & 1.212 \\
\hline Heart disease $(=1)$ & -0.371 & 0.232 & 2.555 & 1 & 0.110 & 0.690 & 0.438 & 1.088 \\
\hline General symptoms $(=1)$ & 0.628 & 0.288 & 4.759 & 1 & 0.029 & 1.873 & 1.066 & 3.292 \\
\hline Nasal symptoms (=1) & 0.363 & 0.211 & 2.951 & 1 & 0.086 & 1.437 & 0.950 & 2.173 \\
\hline Constant & -0.829 & 0.289 & 8.228 & 1 & 0.004 & 0.436 & & \\
\hline
\end{tabular}


Table 8 Multivariable binary logistic regression analysis for predictors of partial/complete recovery of smell/taste in COVID-19 patients

\begin{tabular}{|c|c|c|c|c|c|c|c|c|}
\hline \multirow[t]{2}{*}{ Variable } & \multirow[t]{2}{*}{ B } & \multirow[t]{2}{*}{ SE } & \multirow[t]{2}{*}{ Wald } & \multirow[t]{2}{*}{ df } & \multirow[t]{2}{*}{$p$-value } & \multirow[t]{2}{*}{$\operatorname{Exp}(B)$} & \multicolumn{2}{|c|}{$95 \% \mathrm{Cl}$ for $\operatorname{Exp}(\mathrm{B})$} \\
\hline & & & & & & & Lower & Upper \\
\hline Age $>50$ years $(=1)$ & -0.737 & 0.421 & 3.071 & 1 & 0.080 & 0.478 & 0.210 & 1.091 \\
\hline Chronic pulmonary disease $(=1)$ & -0.400 & 0.497 & 0.649 & 1 & 0.421 & 0.670 & 0.253 & 1.775 \\
\hline Constant & 2.658 & 0.308 & 74.307 & 1 & $<0.001$ & 14.272 & & \\
\hline
\end{tabular}

95\% Cl 95\% confidence interval, $B$ regression coefficient, $d f$ degree of freedom, Exp(B) odds ratio, SE standard error, Wald Wald chi-squared statistic

Table 9 Factors associated with complete recovery of smell/ taste in COVID-19 patients

\begin{tabular}{|c|c|c|c|c|c|}
\hline \multirow[t]{2}{*}{ Variable } & \multicolumn{2}{|c|}{$\begin{array}{l}\text { No or partial } \\
\text { improvement } \\
(n=116)\end{array}$} & \multicolumn{2}{|c|}{$\begin{array}{l}\text { Complete } \\
\text { recovery ( } \mathrm{n} \\
=177) \\
\end{array}$} & \multirow[t]{2}{*}{$p$-value ${ }^{\dagger}$} \\
\hline & $n$ & $\%$ & $N$ & $\%$ & \\
\hline Female sex & 72 & $62.1 \%$ & 111 & $62.7 \%$ & 0.912 \\
\hline Age $>50$ years & 51 & $44.0 \%$ & 53 & $29.9 \%$ & 0.014 \\
\hline Smoking & 8 & $6.9 \%$ & 31 & $17.5 \%$ & 0.009 \\
\hline Chronic pulmonary disease & 18 & $15.5 \%$ & 22 & $12.4 \%$ & 0.452 \\
\hline Heart disease & 29 & $25.0 \%$ & 25 & $14.1 \%$ & 0.019 \\
\hline $\mathrm{DM}$ & 0 & $0.0 \%$ & 6 & $3.4 \%$ & $0.085^{\ddagger}$ \\
\hline General symptoms & 111 & $95.7 \%$ & 158 & $89.3 \%$ & 0.050 \\
\hline Nasal symptoms & 41 & $35.3 \%$ & 44 & $24.9 \%$ & 0.053 \\
\hline
\end{tabular}

Data are numbers $(n)$ and percentages (\%)

${ }^{\dagger}$ Pearson chi-squared test unless otherwise specified

${ }^{\ddagger}$ Fisher's exact test

That is why rapid recovery is evident in SARS-CoV-2 infection-related olfactory/gustatory dysfunctions [19, $22]$. We found that the median time to start recovery was 3 days, and the median time to best recovery was 22 days, and this goes by the latter hypothesis.

Regarding COVID-19 manifestations, fever (56.0\%) was the most common manifestation followed by cough
(45.4\%), headache (39.2\%), and fatigue (37.8\%). These results are close to those reported by Wang et al. [23].

In terms of recovery of olfactory/gustatory dysfunctions after a 6-month follow-up, $60.4 \%$ of patients recovered completely and $28 \%$ of patients recovered partially while $11.6 \%$ of patients did not recover. Nearly the same results were reported by Teaima et al. [8] who found that $66 \%$ of patients recovered completely and $22.1 \%$ recovered partially while $11.9 \%$ did not recover over a 6 -month period follow-up. Another study over a 12-month followup was conducted by Boscolo-Rizzo et al. [14] who found $69.5 \%$ of patients had complete recovery after, $21.9 \%$ had partial recovery, and $8.6 \%$ had no improvement.

In our study, we calculated the time to achieve the best recovery of OD/GD either partial or complete, and we found that the median time to best recovery was 22 days ( $95 \% C I=19$ to 24$)$. Our results are similar to those reported by Meini et al. [10] who found that recovery time from OD/GD in hospitalized patients was rapid (14 to 26 days) and also Chary et al. [20] who reported that the median complete recovery time was 15 days (4 to 27). Given the high rate of rapid recovery, we agree with Vaira et al. [24] who hypothesized that the olfactory dysfunction is not due to neuronal cells injury. A limitation of our study was that patients did not have an objective assessment for OD/GD; also, a longer period of follow-up with a larger cohort is recommended.

Table 10 Multivariable binary logistic regression analysis for predictors of complete recovery of smell/taste in COVID-19 patients

\begin{tabular}{|c|c|c|c|c|c|c|c|c|}
\hline \multirow[t]{2}{*}{ Variable } & \multirow[t]{2}{*}{ B } & \multirow[t]{2}{*}{ SE } & \multirow[t]{2}{*}{ Wald } & \multirow[t]{2}{*}{ df } & \multirow[t]{2}{*}{$p$-value } & \multirow[t]{2}{*}{$\operatorname{Exp}(B)$} & \multicolumn{2}{|c|}{$95 \% \mathrm{Cl}$ for $\operatorname{Exp}(\mathrm{B})$} \\
\hline & & & & & & & Lower & Upper \\
\hline Age $>50$ years $(=1)$ & -0.541 & 0.299 & 3.285 & 1 & 0.070 & 0.582 & 0.324 & 1.045 \\
\hline Smoking $(=1)$ & 1.283 & 0.434 & 8.719 & 1 & 0.003 & 3.606 & 1.539 & 8.450 \\
\hline Heart disease $(=1)$ & -0.302 & 0.363 & 0.696 & 1 & 0.404 & 0.739 & 0.363 & 1.504 \\
\hline $\mathrm{DM}(=1)$ & 21.093 & 15981.299 & 0.000 & 1 & 0.999 & $1.45 \mathrm{E}+09$ & 0.000 & NC \\
\hline 56 general symptoms $(=1)$ & -0.681 & 0.546 & 1.551 & 1 & 0.213 & 0.506 & 0.174 & 1.477 \\
\hline Nasal symptoms (=1) & -0.454 & 0.282 & 2.584 & 1 & 0.108 & 0.635 & 0.365 & 1.105 \\
\hline Constant & 1.150 & 0.516 & 4.975 & 1 & 0.026 & 3.158 & & \\
\hline
\end{tabular}




\section{Conclusion}

Olfactory/gustatory dysfunctions should be recognized for early detection of COVID-19 infection. Most recovery of olfactory/gustatory dysfunction in COVID-19 infection starts within 3 days and reaches the best recovery within 19 to 24 days. Female gender and presence of general symptoms are associated with olfactory/gustatory dysfunctions in the hospitalized COVID-19 patients.

\begin{abstract}
Abbreviations
COVID-19: Coronavirus disease 2019; OD: Olfactory dysfunctions; GD: Gustatory dysfunctions; REC: Research Ethics Committee; RT-PCR: Reverse transcriptase polymerase chain reaction; URTI: Upper respiratory tract infection; DM: Diabetes mellitus; Cl: Confidence interval.
\end{abstract}

\section{Acknowledgements}

We would like to express our appreciation to the residents of our departments, especially Mohammed Talaat and Merna Nabil for their help and support.

\section{Authors' contributions}

All authors had full access to all of the data in the study and take responsibility for the integrity of the data and the accuracy of the data analysis. MSM: concept and design, acquisition and interpretation of the data, drafting of the manuscript, critical revision of the manuscript for important intellectual content, and supervision. MST: concept and design, interpretation of the data, drafting of the manuscript, critical revision of the manuscript for important intellectual content, and supervision. OIM: concept and design, interpretation of the data, drafting of the manuscript, critical revision of the manuscript for important intellectual content, and supervision. MA: interpretation of the data, drafting of the manuscript, and critical revision of the manuscript for important intellectual content. TAH: acquisition and interpretation of the data, drafting of the manuscript, and critical revision of the manuscript for important intellectual content. WFE: interpretation of the data and critical revision of the manuscript for important intellectual content. AHM: acquisition and interpretation of the data and critical revision of the manuscript for important intellectual content. MR: acquisition and interpretation of the data and critical revision of the manuscript for important intellectual content. MFS: interpretation of the data, drafting of the manuscript, and critical revision of the manuscript for important intellectual content. MMN: acquisition and interpretation of the data, drafting of the manuscript, and critical revision of the manuscript for important intellectual content. The authors read and approved the final manuscript.

\section{Funding}

No funding to be declared

\section{Availability of data and materials}

The datasets used during the current study are available from the corresponding author on reasonable request.

\section{Declarations}

Ethics approval and consent to participate

Ethical approval for the current study protocol was obtained from Ain Shams University Faculty of Medicine Research Ethics Committee (REC) FWA 00017585 with reference number FMASU P46a/2020. Informed written consent to participate in the study was provided by all participants.

\section{Consent for publication}

Written consent for publication is taken from all participants.

\section{Competing interests}

Dr. Mohamed Shehata Taha and Dr. Mohamed Amir are co-authors of this study and editorial board members of the journal. They declare competing interests for this submission. They have not handled this manuscript. The rest of the authors declare that they have no competing interests.

Received: 3 January 2022 Accepted: 11 January 2022

Published online: 05 February 2022

\section{References}

1. Li Q, Guan X, Wu P et al (2020) Early transmission dynamics in Wuhan, China, of novel coronavirus-infected pneumonia. N Engl J Med 382(13):1199. https://doi.org/10.1056/NEJMOA2001316

2. Guan W, Ni Z, Hu Y et al (2020) Clinical characteristics of coronavirus disease 2019 in China. N Engl J Med 382(18):1708-1720. https://doi.org/ 10.1056/NEJMOA2002032

3. Lovato A, de Filippis C, Marioni G (2020) Upper airway symptoms in coronavirus disease 2019 (COVID-19). Am J Otolaryngol 41(3):102474. https:// doi.org/10.1016/j.amjoto.2020.102474

4. Mao L, Jin H, Wang M et al (2020) Neurologic manifestations of hospitalized patients with coronavirus disease 2019 in Wuhan, China. JAMA Neurol 77(6):683-690. https://doi.org/10.1001/JAMANEUROL.2020.1127

5. Lechien JR, Chiesa-Estomba CM, De Siati DR et al (2020) Olfactory and gustatory dysfunctions as a clinical presentation of mild-to-moderate forms of the coronavirus disease (COVID-19): a multicenter European study. Eur Arch Oto-Rhino-Laryngology 277(8):2251-2261. https://doi. org/10.1007/s00405-020-05965-1

6. Lee Y, Min P, Lee S, Kim SW (2020) Prevalence and duration of acute loss of smell or taste in COVID-19 patients. J Korean Med Sci 35(18):e174. https://doi.org/10.3346/jkms.2020.35.e174

7. Printza A, Constantinidis J (2020) The role of self-reported smell and taste disorders in suspected COVID-19. Eur Arch Oto-Rhino-laryngology 277(9):2625-2630. https://doi.org/10.1007/s00405-020-06069-6

8. Teaima AA, Salem OM, Teama MAEM et al (2022) Patterns and clinical outcomes of olfactory and gustatory disorders in six months: prospective study of 1031 COVID-19 patients. Am J Otolaryngol 43(1):103259. https:// doi.org/10.1016/j.amjoto.2021.103259

9. Qiu C, Cui C, Hautefort C et al (2020) Olfactory and gustatory dysfunction as an early identifier of COVID-19 in adults and children: an international multicenter study. Otolaryngol Head Neck Surg 163(4):714-721. https:// doi.org/10.1177/0194599820934376

10. Meini S, Suardi LR, Busoni M, Roberts AT, Fortini A (2020) Olfactory and gustatory dysfunctions in 100 patients hospitalized for COVID-19: sex differences and recovery time in real-life. Eur Arch Oto-Rhino-laryngology 277(12):3519-3523. https://doi.org/10.1007/s00405-020-06102-8

11. Saniasiaya J, Islam MA, Abdullah B (2021) Prevalence of olfactory dysfunction in coronavirus disease 2019 (COVID-19): a meta-analysis of 27,492 patients. Laryngoscope. 131(4):865-878. https://doi.org/10.1002/lary. 29286

12. Lefèvre N, Corazza F, Valsamis J et al (2019) The number of X chromosomes influences inflammatory cytokine production following toll-like receptor stimulation. Front Immunol 10:1052. https://doi.org/10.3389/ fimmu.2019.01052

13. Lechien JR, Chiesa-Estomba CM, De Siati DR et al (2020) Olfactory and gustatory dysfunctions as a clinical presentation of mild-to-moderate forms of the coronavirus disease (COVID-19): a multicenter European study. Eur Arch Oto-Rhino-Laryngology 277(8):2251-2261. https://doi. org/10.1007/S00405-020-05965-1/FIGURES/4

14. Boscolo-Rizzo P, Guida F, Polesel J et al (2021) Self-reported smell and taste recovery in COVID-19 patients: a one-year prospective study. https://doi.org/10.1101/2021.03.18.21253862

15. Hopkins C, Surda P, Whitehead E, Kumar BN (2020) Early recovery following new onset anosmia during the COVID-19 pandemic - an observational cohort study. J Otolaryngol - Head Neck Surg = Le J d'otorhino-laryngologie Chir cervico-faciale 49(1):26. https://doi.org/10.1186/ s40463-020-00423-8

16. Paderno A, Mattavelli D, Rampinelli V et al (2020) Olfactory and gustatory outcomes in COVID-19: a prospective evaluation in nonhospitalized subjects. Otolaryngol Neck Surg 163(6):1144-1149. https://doi.org/10. 1177/0194599820939538

17. Qiu C, Cui C, Hautefort C et al (2020) Olfactory and gustatory dysfunction as an early identifier of COVID-19 in adults and children: an international 
multicenter study. Otolaryngol Neck Surg 163(4):714-721. https://doi. org/10.1177/0194599820934376

18. Al-Ani RM, Acharya D (2020) Prevalence of anosmia and ageusia in patients with COVID-19 at a primary health center, Doha, Qatar. Indian J Otolaryngol Head Neck Surg:1-7. https://doi.org/10.1007/ s12070-020-02064-9

19. Vaira LA, Deiana G, Fois AG et al (2020) Objective evaluation of anosmia and ageusia in COVID-19 patients: single-center experience on 72 cases. Head Neck 42(6):1252-1258. https://doi.org/10.1002/hed.26204

20. Chary E, Carsuzaa F, Trijolet J-P et al (2020) Prevalence and recovery from olfactory and gustatory dysfunctions in COVID-19 infection: a prospective multicenter study. Am J Rhinol Allergy 34(5):686-693. https://doi.org/10. $1177 / 1945892420930954$

21. Yan CH, Faraji F, Prajapati DP, Boone CE, DeConde AS (2020) Association of chemosensory dysfunction and COVID-19 in patients presenting with influenza-like symptoms. Int Forum Allergy Rhinol 10(7):806-813. https:// doi.org/10.1002/alr.22579

22. Butowt R, von Bartheld CS (2021) Anosmia in COVID-19: underlying mechanisms and assessment of an olfactory route to brain infection. Neurosci Rev J bringing Neurobiol Neurol psychiatry 27(6):582-603. https://doi.org/10.1177/1073858420956905

23. Wang Z, Yang B, Li Q, Wen L, Zhang R (2020) Clinical features of 69 cases with coronavirus disease 2019 in Wuhan, China. Clin Infect Dis 71(15):769-777. https://doi.org/10.1093/cid/ciaa272

24. Vaira LA, Salzano G, Fois AG, Piombino P, De Riu G (2020) Potential pathogenesis of ageusia and anosmia in COVID-19 patients. Int Forum Allergy Rhinol 10(9):1103-1104. https://doi.org/10.1002/alr.22593

\section{Publisher's Note}

Springer Nature remains neutral with regard to jurisdictional claims in published maps and institutional affiliations.

\section{Submit your manuscript to a SpringerOpen ${ }^{\odot}$ journal and benefit from:}

- Convenient online submission

- Rigorous peer review

- Open access: articles freely available online

- High visibility within the field

- Retaining the copyright to your article

Submit your next manuscript at $\boldsymbol{\nabla}$ springeropen.com 